Case Report

\title{
Hyperchloremic Metabolic Acidosis due to Cholestyramine: A Case Report and Literature Review
}

\author{
Fareed B. Kamar ${ }^{1}$ and Rory F. McQuillan ${ }^{2}$ \\ ${ }^{1}$ University of Calgary, Suite G15, 1403-29 Street NW, Calgary, AB, Canada T2N 2T9 \\ ${ }^{2}$ University of Toronto and University Health Network, Toronto General Hospital, Room 8N-842, 200 Elizabeth Street, \\ Toronto, ON, Canada M5G 2 C4
}

Correspondence should be addressed to Fareed B. Kamar; fbkamar@ucalgary.ca

Received 13 July 2015; Accepted 30 August 2015

Academic Editor: Yoshihide Fujigaki

Copyright (c) 2015 F. B. Kamar and R. F. McQuillan. This is an open access article distributed under the Creative Commons Attribution License, which permits unrestricted use, distribution, and reproduction in any medium, provided the original work is properly cited.

Cholestyramine is a bile acid sequestrant that has been used in the treatment of hypercholesterolemia, pruritus due to elevated bile acid levels, and diarrhea due to bile acid malabsorption. This medication can rarely cause hyperchloremic nonanion gap metabolic acidosis, a complication featured in this report of an adult male with concomitant acute kidney injury. This case emphasizes the caution that must be taken in prescribing cholestyramine to patients who may also be volume depleted, in renal failure, or taking spironolactone.

\section{Introduction}

The orally administered medication cholestyramine is a nonabsorbable anion exchange resin that serves as a bile acid sequestrant. It has been used in the treatment of hypercholesterolemia, pruritus due to biliary obstruction and elevated bile acid levels, and diarrhea due to bile acid malabsorption in the setting of ileal disease or resection [1]. Adverse effects are uncommon, though typical gastrointestinal reactions include constipation, nausea, and flatulence [1]. A handful of reports have described the rare complication of metabolic acidosis [1-11]. The following case adds to this literature in describing the occurrence of hyperchloremic nonanion gap metabolic acidosis in a 45-year-old male liver transplant patient on cholestyramine for pruritus who developed acute kidney injury.

\section{Case Presentation}

A 45-year-old Caucasian man was admitted to hospital for an elective biliary drain insertion for his recurrent bile duct stricture since a liver transplant seven years earlier. Because of the chronic cholestasis, he had been taking cholestyramine $4 \mathrm{~g}$ PO TID for his pruritus.
Days after the biliary drain insertion, the patient developed acute kidney injury (creatinine of $261 \mu \mathrm{mol} / \mathrm{L}$ ), in the setting of an Enterococcus faecium bacteremia. At this time, the serum $\mathrm{pH}$ was 7.09 and serum electrolytes were as follows: sodium $140 \mathrm{mmol} / \mathrm{L}$, potassium $3.9 \mathrm{mmol} / \mathrm{L}$, chloride $118 \mathrm{mmol} / \mathrm{L}$, and bicarbonate $12 \mathrm{mmol} / \mathrm{L}$ (anion gap $10 \mathrm{mmol} / \mathrm{L}$ ). The urine $\mathrm{pH}$ was 5.5 and the urinalysis was positive for bilirubin, proteinuria $(1.0 \mathrm{~g} / \mathrm{L})$, and hemegranular casts. The urine electrolytes were as follows: sodium $48 \mathrm{mmol} / \mathrm{L}$, potassium $30 \mathrm{mmol} / \mathrm{L}$, and chloride $57 \mathrm{mmol} / \mathrm{L}$ (urine anion gap $21 \mathrm{mmol} / \mathrm{L}$ ). No phosphaturia or glycosuria was noted.

Having discontinued the cholestyramine, he was given intravenous sodium bicarbonate, and his hyperchloremic metabolic acidosis resolved.

\section{Discussion}

Cholestyramine is a resin that exchanges anions once orally administered by way of its ammonium groups. It swaps chloride anions for bile acids in the lumen of the small intestine, resulting in bile acid complexes that are excreted fecally instead of being reabsorbed in the ileum [10, 12]. 
TABLE 1: Summary of the literature describing cholestyramine-induced hyperchloremic metabolic acidosis.

\begin{tabular}{|c|c|c|c|c|c|c|}
\hline Age & $\begin{array}{l}\text { Sex (male }(\mathrm{M}) \\
\text { female }(\mathrm{F}))\end{array}$ & Serum $\mathrm{pH}$ & $\begin{array}{l}\text { Chloride } \\
(\mathrm{mmol} / \mathrm{L})\end{array}$ & $\begin{array}{l}\text { Bicarbonate } \\
(\mathrm{mmol} / \mathrm{L})\end{array}$ & Precipitating factors & Case reference \\
\hline 1.5 days & $M$ & 7.15 & 125 & 9 & Diarrhea & [6] \\
\hline 4 weeks & $\mathrm{F}$ & - & 128 & 19 & Diarrhea & {$[9]$} \\
\hline 5 weeks & M & 6.83 & 130 & 5.4 & Volume depletion, renal failure & {$[8]$} \\
\hline 13 weeks & M & 7.28 & 145 & 15 & Upper respiratory tract infection, diarrhea & {$[9]$} \\
\hline 6 months & M & 6.88 & 112 & - & Upper respiratory tract infection & {$[2]$} \\
\hline 10.5 years & $\mathrm{F}$ & 7.18 & 114 & 9 & Renal failure & {$[7]$} \\
\hline 45 years & M & 7.09 & 118 & 12 & Bacteremia, renal failure & Case presentation \\
\hline 45 years & M & 7.12 & 127 & 8 & Renal failure & {$[5]$} \\
\hline 51 years & $\mathrm{F}$ & - & 115 & 8 & Spironolactone & {$[10]$} \\
\hline 57 years & M & - & 122 & 11 & Diarrhea & {$[10]$} \\
\hline 70 years & $\mathrm{F}$ & 7.15 & 128 & 5 & $\begin{array}{l}\text { Upper respiratory tract infection, renal } \\
\text { failure, and spironolactone }\end{array}$ & {$[1]$} \\
\hline 70 years & $\mathrm{F}$ & 7.34 & 119 & 14 & Spironolactone & {$[4]$} \\
\hline
\end{tabular}

This exchange causes gastrointestinal secretion of bicarbonate and absorption of chloride, mediated by the duodenal brush border's apical chloride/bicarbonate antiporter [13]. The effect of this resin on chloride and bicarbonate in the gastrointestinal tract alone does not, however, lead to hyperchloremic metabolic acidosis, since the kidneys can compensate by increasing chloride excretion and bicarbonate retention. These compensatory mechanisms are impeded in states of impaired urinary acidification such as renal insufficiency and aldosterone antagonism [10, 14], which unmask cholestyramine-induced hyperchloremia and bicarbonate loss. In this report, the patient's impaired urinary acidification, as evidenced by a positive urine anion gap, was the result of renal insufficiency.

Other reported cases of cholestyramine-induced hyperchloremic metabolic acidosis have occurred in children with renal impairment $[7,8]$ and volume depletion (a probable cause of renal impairment) in the setting of infection $[2,9]$ and diarrhea $([6,9]$, see Table 1$)$. Adult cases of metabolic acidosis in the context of cholestyramine use have also been described in the setting of renal insufficiency $[1,5,10]$ and spironolactone use $([1,4,10,11]$, see Table 1$)$.

This case and literature review highlight the complication of hyperchloremic metabolic acidosis that may occur with cholestyramine use in adult and pediatric patients. Patients taking this medication should have their electrolytes monitored, particularly in the setting a precipitating factor such as renal failure, volume depletion, and spironolactone use. If this complication occurs along with no other identified causes, then cholestyramine should be stopped, precipitants should be addressed, and sodium bicarbonate could be administered.

\section{Conflict of Interests}

The authors declare that there is no conflict of interests regarding the publication of this paper.

\section{References}

[1] E. R. Eaves and M. G. Korman, "Cholestyramine induced hyperchloremic metabolic acidosis," Australian and New Zealand Journal of Medicine, vol. 14, no. 5, pp. 670-672, 1984.

[2] B. Bernsten and S. Zoger, "Hyperchloremic metabolic acidosis with cholestyramine therapy for biliary cholestasis," The American Journal of Diseases of Children, vol. 132, no. 12, p. 1220, 1978.

[3] H. J. Blom and E. Monasch, "Metabolic acidosis in a patient with kidney dysfunction following administration of cholestyramine," Nederlands Tijdschrift voor Geneeskunde, vol. 127, no. 32, pp. 1446-1447, 1983.

[4] W. M. Clouston and H. M. Lloyd, "Cholestyramine induced hyperchloremic metabolic acidosis," Australian and New Zealand Journal of Medicine, vol. 15, no. 2, article 271, 1985.

[5] F. S. Y. Fan, K. M. Chow, C. C. Szeto, and P. K. T. Li, "Hyperchloraemic metabolic acidosis," Emergency Medicine Journal, vol. 25, no. 9, article 613, 2008.

[6] J. V. Hartline, "Hyperchloremia, metabolic acidosis, and cholestyramine," The Journal of Pediatrics, vol. 89, no. 1, p. 155, 1976.

[7] P. K. Kleinman, "Letter: cholestyramine and metabolic acidosis," The New England Journal of Medicine, vol. 290, no. 15, article 861, 1974.

[8] M. Pattison and S. M. Lee, "Life-threatening metabolic acidosis from cholestyramine in an infant with renal insufficiency," The American Journal of Diseases of Children, vol. 141, no. 5, pp. 479480, 1987.

[9] W. A. Primack, L. M. Gartner, H. E. McGurk, and A. Spitzer, "Hypernatremia associated with cholestyramine therapy," The Journal of Pediatrics, vol. 90, no. 6, pp. 1024-1025, 1977.

[10] P. J. Scheel Jr., A. Whelton, K. Rossiter, and A. Watson, "Cholestyramine-induced hyperchloremic metabolic acidosis," Journal of Clinical Pharmacology, vol. 32, no. 6, pp. 536-538, 1992.

[11] P. Zapater and D. Alba, "Acidosis and extreme hyperkalemia associated with cholestyramine and spironolactone," Annals of Pharmacotherapy, vol. 29, no. 2, pp. 199-200, 1995. 
[12] W. G. Thompson, "Cholestyramine," Canadian Medical Association journal, vol. 104, no. 4, pp. 305-309, 1971.

[13] Z. Wang, S. Petrovic, E. Mann, and M. Soleimani, "Identification of an apical $\mathrm{Cl}^{-} / \mathrm{HCO}_{3}^{-}$exchanger in the small intestine," American Journal of Physiology-Gastrointestinal and Liver Physiology, vol. 282, no. 3, pp. G573-G579, 2002.

[14] M. A. Manuel, G. J. Beirne, J. P. Wagnild, and M. W. Weiner, "An effect of spironolactone on urinary acidification in normal man," Archives of Internal Medicine, vol. 134, no. 3, pp. 472-474, 1974. 


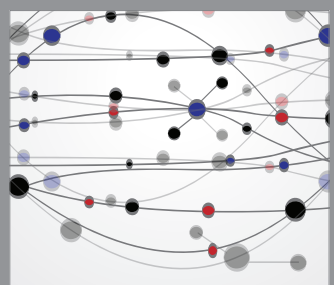

The Scientific World Journal
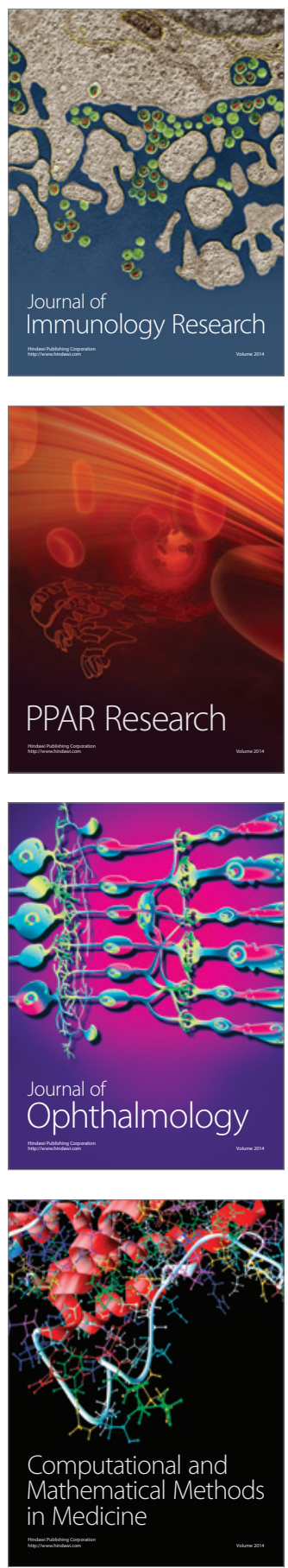

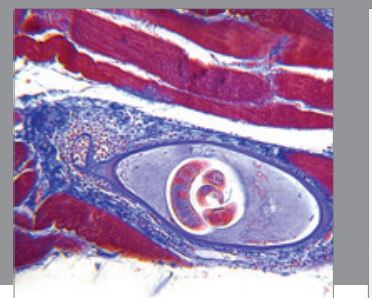

Gastroenterology

Research and Practice
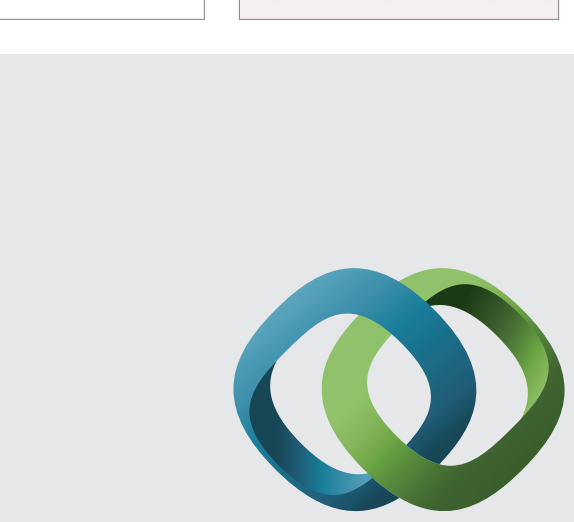

\section{Hindawi}

Submit your manuscripts at

http://www.hindawi.com
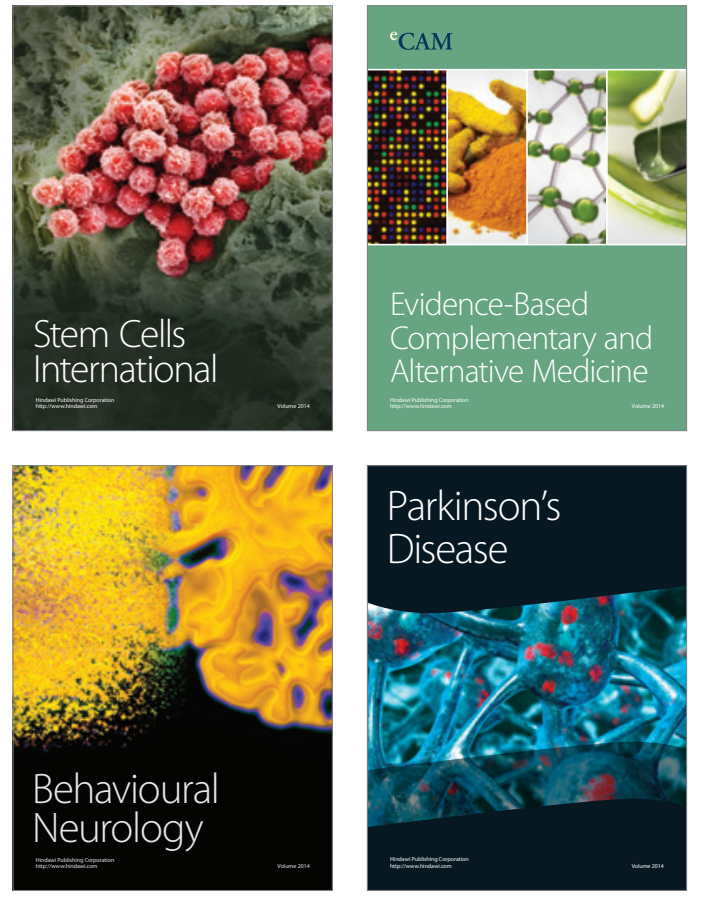
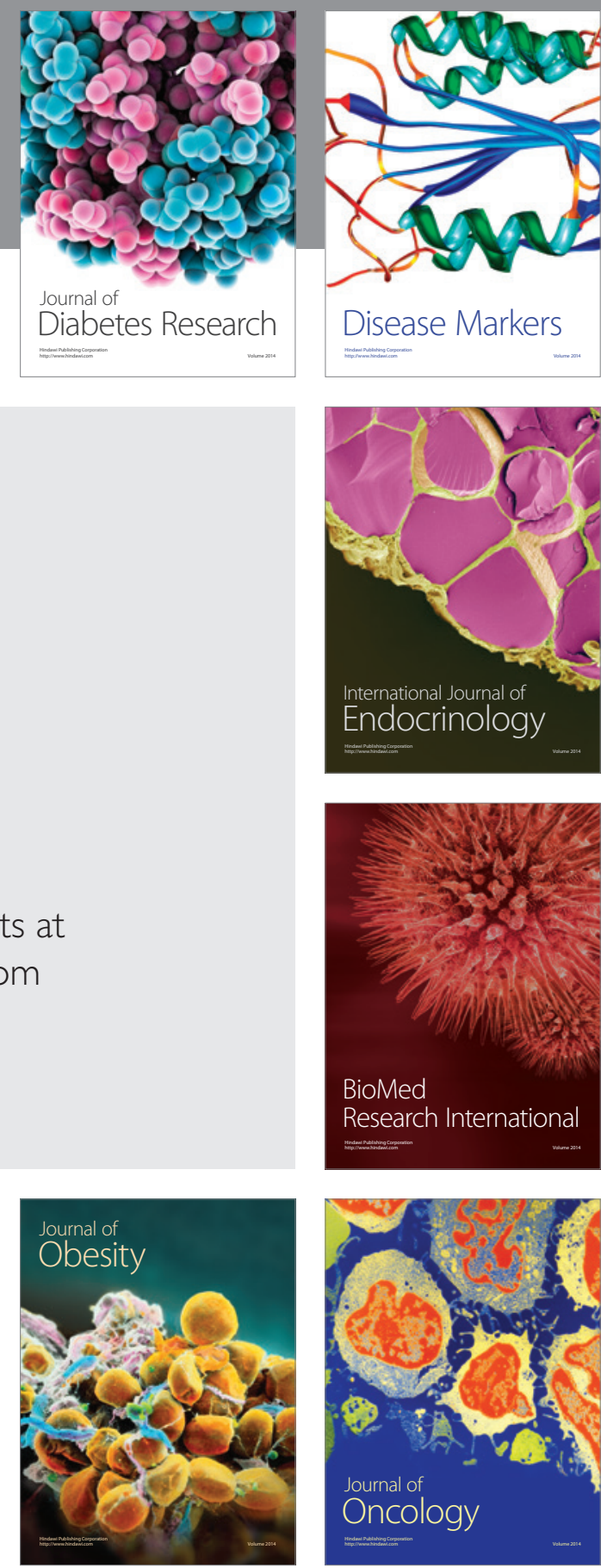

Disease Markers
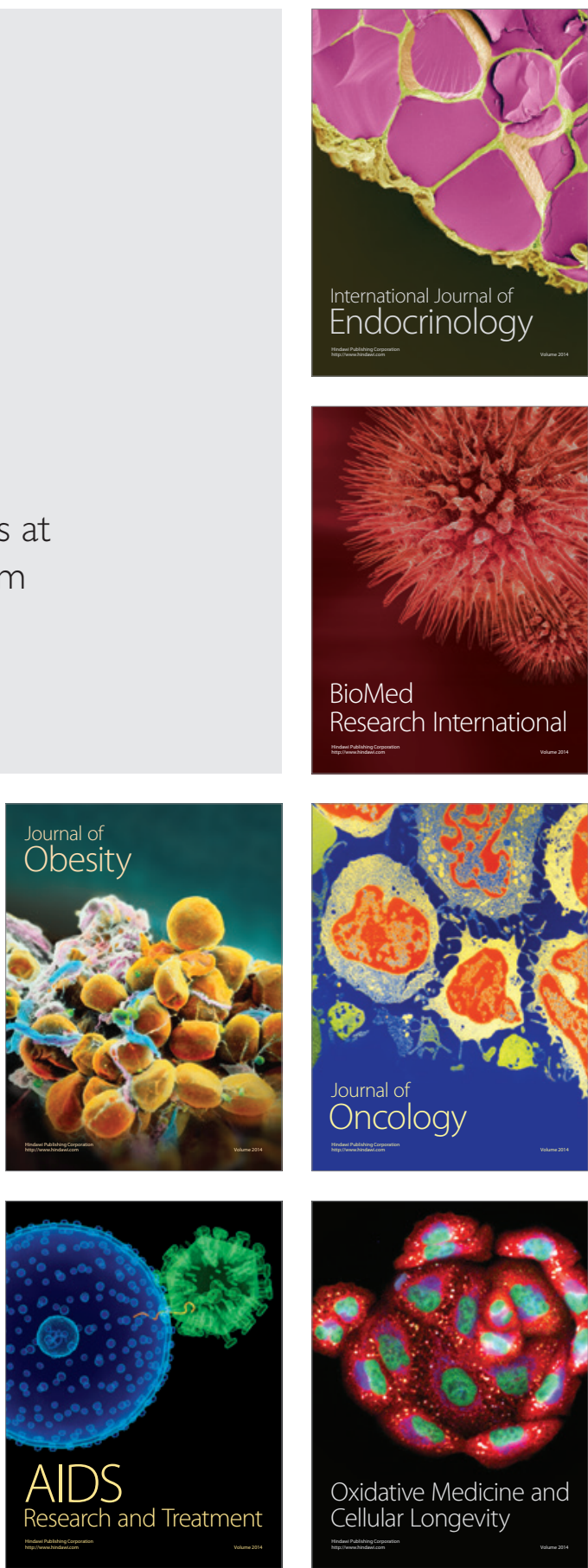